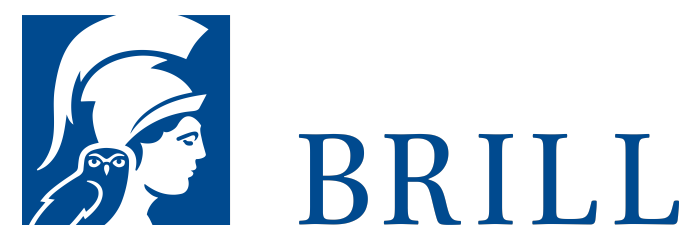

\title{
Die Tode der Fotografie I
}

Totenfotografie und ihr sozialer Gebrauch

Author: Katharina Sykora

Was verstehen wir vom Tod, wenn wir Fotografien von Verstorbenen betrachten? Und wen oder was sehen wir dabei? Wie gehen wir mit den Fotos um? Wo platzieren wir sie, wem zeigen wir sie, wo verbergen wir sie? Welche Art Beziehung unterhalten wir zu den Toten mit Hilfe ihrer Fotografien, und wie verständigen wir uns über sie? Ist uns dabei das Medium präsent, oder bleibt es eine durchsichtige Membran? Das vorliegende Buch geht diesen Fragen nach und untersucht den sozialen Umgang mit Totenfotografien unserer westlichen Bestattungs- und Erinnerungsriten seit der Erfindung des Mediums. Ihm folgt ein zweiter Band, der analysiert, wie die Fototheorie und viele Fotokünstler und -künstlerinnen sich dem Thema nähern.

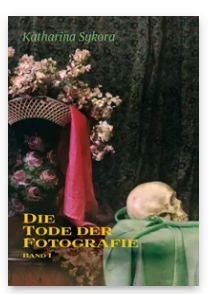

Pages: 603 Seiten, $200 \mathrm{~s} / \mathrm{w}$ und 25 farb. Abb. Language:

German

Subjects: General, Media

\section{Studies}

Publisher: Brill | Fink

E-Book (PDF)

Released online: 16 Sep 2019

ISBN: 978-3-

8467-4915-9

List price

USD $\$ 92.00$

Hardback

Publication date: o7 Oct 2009

ISBN: 978-3-

7705-4915-3

List price

USD \$92.00 
Katharina Sykora hat Kunstgeschichte, Romanistik und Pädagogik an den Universitäten Würzburg und Heidelberg studiert. Anschließend hat sie über das Phänomen des Seriellen in der Kunst promoviert. Sie war Wissenschaftliche Mitarbeiterin im Feministischen Archiv und Dokumentationszentrum Frankfurt a.M. (Rheemtsma Stiftung) sowie an der Kunsthalle Mannheim und hatte Lehraufträge an den Universitäten Frankfurt a.M., Heidelberg, Zürich, Marburg und Trier. Zudem war sie Professorin für mittlere und neuere Kunstgeschichte mit dem Schwerpunkt Geschlechterforschung an der Ruhr-Universität Bochum. Seit 2001 ist sie Professorin für Kunstgeschichte des 19. und 20. Jahrhunderts am Institut für Kunstwissenschaft der Hochschule für Bildende Künste Braunschweig.

For more information see brill.com

Order information: Order online at brill.com +44330 333 oo49 | customerservices@brill.com Submission information: brill.com/authors

Titles published by Brill | Fink, Brill | mentis or Brill | Schöningh: +49(o)71 5413279216 | brill@brocom.de 